\title{
DETERMINATION OF FREQUENCY OF A NOVEL DIAGNOSTIC CATEGORY OF HYPERGLYCEMIA I.E. IMPAIRED RANDOM GLUCOSE IN PREVIOUSLY UNKNOWN PATIENTS OF PREDIABETES AND DIABETES MELLITUS
}

\author{
Qurat Ul Ain Mustafa, Muhammad Amir, Muhammad Tanvir Sajid*, Zujaja Hina Haroon, Aamir Ijaz, Naveed Asif \\ Armed Forces Institute of Pathology/ National University of Medical Sciences (NUMS) Rawalpindi Pakistan, *Armed Forces Institute of \\ Urology/National University of Medical Sciences (NUMS) Rawalpindi Pakistan
}

\begin{abstract}
Objective: To determine the frequency of normoglycemia (NG), prediabetes and diabetes mellitus (DM) among patients having impaired random glucose (IRG) and establish the optimum cutoff of impaired random glucose for the diagnosis of diabetes and prediabetes.

Study Design: Cross sectional study.

Place and Duration of Study: Armed Forces Institute of Pathology Rawalpindi and Combined Military Hospital Quetta, from Nov 2016 to Nov 2018.

Methodology: Healthy individuals of both genders undergoing investigation for diabetes mellitus were enrolled through non probability consecutive sampling while patients with diabetes, pregnant, hospitalized, using concomitant medications (corticosteroids, immunosuppressive, chemotherapy) and those unable to complete oral glucose tolerance test (OGTT) were excluded. Random plasma glucose (RPG) was determined and patients having impaired random glucose underwent oral glucose tolerance test, analysis being done on ADVIA1800® using hexokinase methodology.

Results: Among the 280 study participants, majority were female $\{156(57.5 \%)$ vs $124(44.3 \%)$ male $\}$. Mean age in male and female patients was $33.625 \pm 3.34$ years vs $35.150 \pm 2.79$ years with $p$-value 0.50 while mean IRG was $7.12 \pm 1.47$ vs $6.90 \pm 1.17 \mathrm{mmol} / \mathrm{L}$ respectively with $p$-value 0.16 (statistically insignificant). Oral glucose tolerance test results showed NG in $61.8 \%$ (173), prediabetes in $24.6 \%$ (69) while diabetes was found in 38 (13.6\%) patients. Optimal impaired random glucose cutoff value for diagnosis of diabetes was found $7.45 \mathrm{mmol} / \mathrm{L}$ (AUC 0.956 [CI 0.927-0.984], $p<0.001$, sensitivity $94.7 \%$, specificity $74.4 \%$ ), however, same cut-off value showed impaired random glucose as fair diagnostic test for prediabetes (AUC 0.771 [CI 0.717-0.825], $p<0.001$, sensitivity $72.5 \%$, specificity $77.3 \%)$.

Conclusion: Random plasma glucose helps diagnose patients at risk of prediabetes and diabetes who may otherwise not be identified. Impaired random glucose $\geq 7.45 \mathrm{mmol} / \mathrm{L}$ was found optimal to initiate definitive testing.
\end{abstract}

Keywords: Diabetes mellitus, Frequency, Glucose tolerance test, Prediabetes.

\footnotetext{
This is an Open Access article distributed under the terms of the Creative Commons Attribution License (http://creativecommons.org/licenses/by/4.0), which permits unrestricted use, distribution, and reproduction in any medium, provided the original work is properly cited.
}

\section{INTRODUCTION}

Diabetes mellitus (DM) is one of the most common chronic diseases occurring in epidemic proportions ${ }^{1}$, requiring multifactorial risk-reduction strategies beyond glycemic control. The international diabetic federation (IDF) has predicted that the number of individuals with DM will increase from 425 million in 2015 to 629 million in 2045 while causing 5.1 million deaths and consuming $\$ 727$ billion in 20172. DM is a major national health problem and Pakistan is among top ten

Correspondence: Dr Muhammad Tanveer Sajid, Classified Surgical Specialist, AFIU Rawalpindi Pakistan

Received: 28 Aug 2019; revised received: 14 Jan 2020; accepted: 16 Jan 2020 countries of the world having greatest number of people having diabetes. According to the Pakistan National Diabetes Survey (PNDS), 9.3\% males and $11.1 \%$ females suffer from DM while other surveys showed slightly higher proportions ${ }^{3}$.

Approximately one third of the patients with diabetes and $90 \%$ with prediabetes remain undiagnosed until complications occur ${ }^{2}$. Prediabetes not only predisposes to DM but also itself is associated with increased risk of stroke, coronary artery disease, peripheral vascular disease, dyslipidemia, hypertension and obesity ${ }^{4}$. American diabetic association (ADA) recommends early 
detection of DM and prediabetes as effective lifestyle/pharmacological interventions available can prevent progression of disease and its complications conserving tremendous amount of resources $^{5}$. Current tests to diagnose DM include blood glucose-based tests and glycated proteins. Fasting plasma glucose (FPG), RPG and OGTT are based on serum glucose while hemoglobin A1C (A1C) is the most useful glycated protein in practice ${ }^{1}$. FPG involves measurement of plasma glucose after overnight fast, being endorsed as test of choice by ADA. It's easy, inexpensive, and highly correlated with diabetic complications. The disadvantages include early morning appointments, requirement for fast, need to process the blood sample promptly $(<2$ hours after collection) and confirmation of results either at second occasion or with another test. RPG is easily obtained, does not require fasting, frequently employed as part of basic metabolic screen by most practicing physicians worldwide 6 . Downsides include prompt processing, additional office visit for confirmatory testing, lack of guidelines for interpretation of RPG levels obtained opportunistically and absence of direct comparison with diabetes-specific complications. OGTT is gold standard most sensitive diagnostic test of choice for diabetes and prediabetes avoiding overlooking of the patients with even mild disturbances in glucose metabolism ${ }^{7}$. However, OGTT is lengthy requiring committed nursing staff, has poor reproducibility and needs 8-hour fast. A1C has recently been endorsed by the ADA as a first-line test for both screening and diagnosis. Test can be performed independent of fasting status and provides an overview of glucose control overs months rather than a single point value ${ }^{8}$.

Many studies have shown that RPG can detect significant proportion of undiagnosed DM and prediabetes when combined with appropriate definitive diagnostic test like OGTT, FPG and A1C ${ }^{9}$. A study conducted by Friedman et al10, in 2013 revealed a frequency of $12.5 \%$ of DM when elevated screening RPG was followed with OGTT while another study conducted by Barasch et al11, revealed frequency of $12.2 \%$ and $5.7 \%$ for $\mathrm{DM}$ and prediabetes respectively when healthy individuals underwent screening RPG.

Limited work was done in Pakistan to identify potential value of RPG for diabetic screening. The primary objective was to determine utility of RPG to diagnose prediabetes and diabetes while secondary objective was to determine optimal cutoff value of IRG at which definitive diagnostic tests should be offered.

\section{METHODOLOGY}

This cross sectional study involved healthy individuals of both gender visiting AFIP/CMH Quetta for investigation of DM from Nov 2016 to Nov 2018. The study protocol was approved by the hospital ethical review Committee (Certificate no EXT-FC-CHP-04/READ-IRB/17/108). Non probability consecutive sampling technique utilized at outpatient department to enroll 280 patients (WHO calculator, confidence interval 95\%, $5 \%$ margin of error and frequency $23.8 \%)^{11}$. Non probability consecutive sampling was followed while patients with diabetes, pregnant, hospitalized, using concomitant medications such as chemotherapy, corticosteroids or immuno-suppressant and those unable to complete oral glucose tolerance test (OGTT) were excluded. A written informed consent obtained from all participants.

ADA guidelines were followed to stratify individuals as having NG, prediabetes or DM. IRG was defined as RPG between 5.6-11 mmol/1 and all having IRG were subjected to confirmatory OGTT free of cost according to WHO guidelines. Samples were collected in properly labeled sample tube with $\mathrm{NaF} / \mathrm{EDTA}$ by researcher themselves and transported to the processing room within half an hour. Glucose concentrations were measured within 2 hours of sample collection usingglucose hexokinase II method (ADVIA $1800 \AA$ Siemens healthcare Diagnostics Inc., 511 Benedict Ave/Tarrytown, NY 10591, USA) following basic principles of photometry as per the manufacturer's instruc-tions and specifications. This kit has a sensitivity / lower limit of detection of $0.11 \mathrm{mmol} / \mathrm{L}$, linearity up to $38.9 \mathrm{mmol} / \mathrm{L}$, Intra-assay coefficient of variation (CV) $0.5 \%$ and 
inter-assay CV 1.3\%. Frequency of NG, prediabetes and DM determined.

Statistical analysis was done using SPSS 24.0. Mean and standard deviation was determined for quantitative variables while qualitative data was reported as numbers and percentages and chisquare test and $t$-test used for inference statistics. Differences among the groups (NG, IGT and DM) were tested by one-way ANOVA. ROC curves were plotted and AUC was calculated. $p$-value $\leq 0.05$ was considered statistically significant.

\section{RESULTS}

Among the 319 study participants recruited, 280 met the inclusion criteria and selected. Majority was female 156 (57.5\%) vs 124 (44.3\%) male.
(81.1\%) individuals while $53(18.9 \%)$ has impaired fasting glucose (IFG). Post glucose challenge analysis showed NG in 173 (61.8\%), IGT in 69 (24.6\%) while DM was found in 38 (13.6\%) patients (table-I). Stratification of NG, IGT and DM with respect to age, gender and IRG performed revealed significantly more chances of IGT and DM if patient was $>40$ years, of female gender and had IRG $>7 \mathrm{mmol} / \mathrm{L}$ at initial presentation (table-II). Frequency distribution revealed that 38 patients $(13.6 \%)$ had diabetes, prediabetes being found in $69(24.6 \%)$ of the total study subjects. Detailed analysis of various subcategories of IRG with respect to OGTT and FPG revealed significantly more diabetes and prediabetes if higher IRG and IFG were found at initial presentation

Table-I: Demographical variables of study participants $(n=280)$.

\begin{tabular}{|c|c|c|c|}
\hline Variable & Male & Female & $p$-value \\
\hline Age (years) (Mean \pm SD) & $40.06 \pm 11.08$ & $39.25 \pm 9.18$ & \\
\hline Gender & $124(44.3 \%)$ & $156(57.5 \%)$ & \\
\hline Impaired Random Glucose IRG (mmol/L) & $7.12 \pm 1.47$ & $6.90 \pm 1.17$ & 0.157 \\
\hline \multicolumn{4}{|l|}{ Fasting Plasma Glucose FPG $(\mathrm{mmol} / \mathrm{L})(\mathrm{n}=280)$} \\
\hline $\begin{array}{l}\text { Normoglycemia (227) }(81.07 \%) \\
\text { Impaired Fasting Glucose IFG (53) }(18.93 \%)\end{array}$ & $\begin{array}{c}104(37.14 \%) \\
20(7.14 \%)\end{array}$ & $\begin{array}{c}123(43.93 \%) \\
33(11.79 \%)\end{array}$ & $<0.001$ \\
\hline \multicolumn{4}{|c|}{ Oral Glucose Tolerance Test OGTT $(\mathrm{mmol} / \mathrm{L})(\mathrm{n}=280)$} \\
\hline $\begin{array}{l}\text { Normoglycemia }(\mathrm{n}=173)(61.8 \%) \\
\text { Prediabetes (69) }(24.6 \%) \\
\text { Diabetes Mellitus DM (38) (13.6\%) }\end{array}$ & $\begin{array}{l}83(29.64 \%) \\
19(6.79 \%) \\
22(7.86 \%)\end{array}$ & $\begin{array}{l}90(32.14 \%) \\
50(17.86 \%) \\
16(5.71 \%)\end{array}$ & $<0.001$ \\
\hline \multicolumn{4}{|c|}{$\begin{array}{l}\text { Table-II: Stratification of Normoglycemia, prediabetes and diabetes with respect to age, gender and impairec } \\
\text { random glucose. }\end{array}$} \\
\hline $\begin{array}{l}\text { Normoglycemia } \\
\quad 173(61.8 \%)\end{array}$ & $\begin{array}{c}\text { Prediabetes } \\
69(24.6 \%)\end{array}$ & $\begin{array}{c}\text { Diabetes Mellitus } \\
38(13.6 \%)\end{array}$ & $p$-value \\
\hline \multicolumn{4}{|l|}{ Age (years) } \\
\hline $\begin{array}{c}128(70.72 \%) \\
45(45.45 \%)\end{array}$ & $\begin{array}{l}37(20.44 \%) \\
32(32.32 \%)\end{array}$ & $\begin{array}{c}16(8.84 \%) \\
22(22.23 \%)\end{array}$ & $<0.001$ \\
\hline \multicolumn{4}{|l|}{ Gender } \\
\hline $\begin{array}{l}83(66.94 \%) \\
90(57.69 \%)\end{array}$ & $\begin{array}{l}19(15.32 \%) \\
50(32.05 \%)\end{array}$ & $\begin{array}{l}22(17.74 \%) \\
16(10.26 \%)\end{array}$ & 0.003 \\
\hline \multicolumn{4}{|l|}{ IRG (mmol/L) } \\
\hline $\begin{array}{c}155(89.08 \%) \\
18(16.98 \%)\end{array}$ & $\begin{array}{c}17(9.77 \%) \\
52(49.06 \%) \\
\end{array}$ & $\begin{array}{c}02(1.15 \%) \\
36(33.96 \%)\end{array}$ & $<0.001$ \\
\hline
\end{tabular}

Mean age in male and female patients was 33.625 \pm 3.34 years vs $35.150 \pm 2.79$ years with $p$-value 0.50 while mean IRG was $7.12 \pm 1.47$ vs $6.90 \pm 1.17$ mmol/L respectively with $p$-value 0.16 (statistically insignificant). FPG measurement preliminary to glucose challenge revealed NG in 227 $(p<0.001)$ (table-III).

ANOVA was performed to compare the impact of IRG on likelihood of being normoglycemics, having prediabeticor diabetes. The differences in the variance between the groups were statistically significant as depicted by 
ANOVA F $(2,300.80), p<0.001$. The magnitude of difference in the means and the effect size was large (partial eta squared $=0.685$ ). A Tukey post hoc analysis revealed that value of IRG was statistically significant different among normoglycemics, patients withprediabetes and diabetes

Table-III: Detailed analysis of Impaired random glucose (IRG) sub categories with oral glucose tolerance test (OGTT) and fasting plasma glucose $(\mathrm{n}=\mathbf{2 8 0})$.

\begin{tabular}{|c|c|c|c|c|}
\hline \multirow{2}{*}{$\begin{array}{l}\text { Category } \\
\text { on OGTT } \\
(\mathrm{n}=280) \\
(100 \%)\end{array}$} & \multirow{2}{*}{$\begin{array}{c}\text { Impaired } \\
\text { Random } \\
\text { Glucose } \\
\text { IRG } \\
(\mathrm{mmol} / \mathrm{L})\end{array}$} & \multicolumn{2}{|c|}{$\begin{array}{c}\text { Fasting Plasma } \\
\text { Glucose }\end{array}$} & \multirow{2}{*}{$\begin{array}{c}p- \\
\text { value }\end{array}$} \\
\hline & & Normal & IFG* & \\
\hline \multirow{6}{*}{$\begin{array}{l}\text { Normoglyc } \\
\text { emia } \\
(173) \\
(61.8 \%)\end{array}$} & $5.6-6$ & 80 & 02 & \multirow{6}{*}{$<.001$} \\
\hline & $6.1-6.5$ & 50 & - & \\
\hline & $6.6-7$ & 17 & 06 & \\
\hline & $7.1-7.5$ & 04 & 04 & \\
\hline & $7.6-8$ & 05 & - & \\
\hline & $>8$ & 02 & 03 & \\
\hline \multirow{6}{*}{$\begin{array}{l}\text { Prediabetes } \\
(69) \\
(24.6 \%)\end{array}$} & $5.6-6$ & 02 & - & \multirow{6}{*}{0.099} \\
\hline & $6.1-6.5$ & 06 & - & \\
\hline & $6.6-7$ & 07 & 02 & \\
\hline & 7.1-7.5 & 12 & 08 & \\
\hline & $7.6-8$ & 15 & 06 & \\
\hline & $>8$ & 11 & - & \\
\hline \multirow{6}{*}{$\begin{array}{l}\text { Diabetes } \\
\text { Mellitus } \\
\text { DM } \\
(38) \\
(13.6 \%)\end{array}$} & $5.6-6$ & - & - & \multirow{6}{*}{0.086} \\
\hline & $6.1-6.5$ & - & - & \\
\hline & $6.6-7$ & - & 02 & \\
\hline & 7.1-7.5 & - & 02 & \\
\hline & $7.6-8$ & 06 & 02 & \\
\hline & $>8$ & 10 & 16 & \\
\hline
\end{tabular}

*Impaired fasting glucose

Table-IV: Comparison impaired random glucose (IRG) in different groups based on oral glucose tolerance test (OGTT).

\begin{tabular}{l|c|c|c}
\hline Variable & IRG (Mean \pm SD mmol/L) & 95\% confidence interval & \multirow{2}{*}{$\boldsymbol{p}$-value } \\
\hline Normoglycemia (173) (61.8\%) & $6.25 \pm 0.64$ & $6.16-6.35$ & \multirow{2}{*}{$<0.001$} \\
\cline { 1 - 3 } Prediabetes (69) (24.6\%) & $7.58 \pm 0.66$ & $7.42-7.74$ & \\
\hline Diabetes mellitus (38) (13.6\%) & $9.35 \pm 1.19$ & $8.96-9.74$ & \\
\hline
\end{tabular}

(NG $6.25 \pm 0.64 \mathrm{CI}=6.16-6.35$, IGT $7.58 \pm 0.66$ $\mathrm{CI}=7.42-7.74, \mathrm{DM} 9.35 \pm 1.19 \mathrm{CI}=8.96-9.74)$ $(p<0.001)$ (table-IV). Upon ROC curve application, optimal IRG cutoff value for diagnosis of DM was found $7.45 \mathrm{mmol} / \mathrm{L}$ (AUC 0.956 [95\% CI 0.927-0.984], $p<0.001$, excellent diagnostic instrument) with sensitivity of $94.7 \%$ and specificity of $74.4 \%$ fig- 1 , however, same cutoff value showed IRG as fair diagnostic test for prediabetes (AUC 0.771 [95\% CI 0.717-0.825], $p<0.001$ ) having sensitivity $72.5 \%$ and specificity $77.3 \%$ (fig-2).

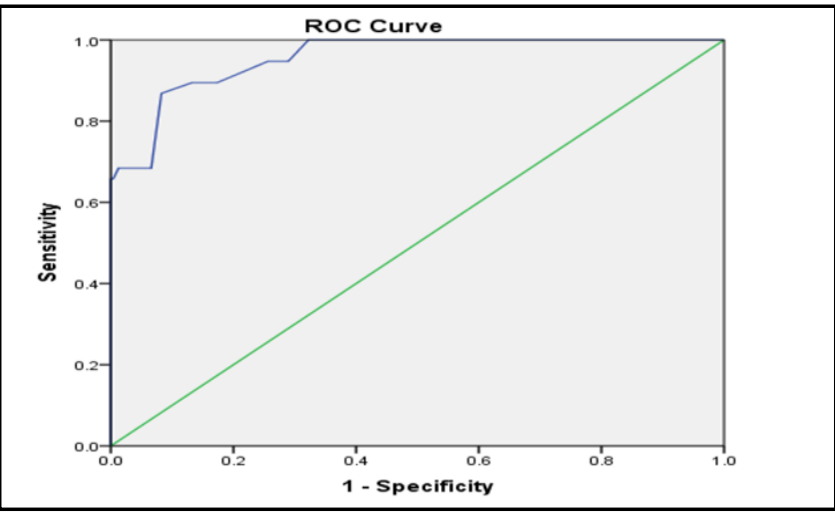

Figure-1: ROC curve showing the AUC of impaired random glucose for diabetes $38(n=280)$ patients are positive for diabetes on OGTT).

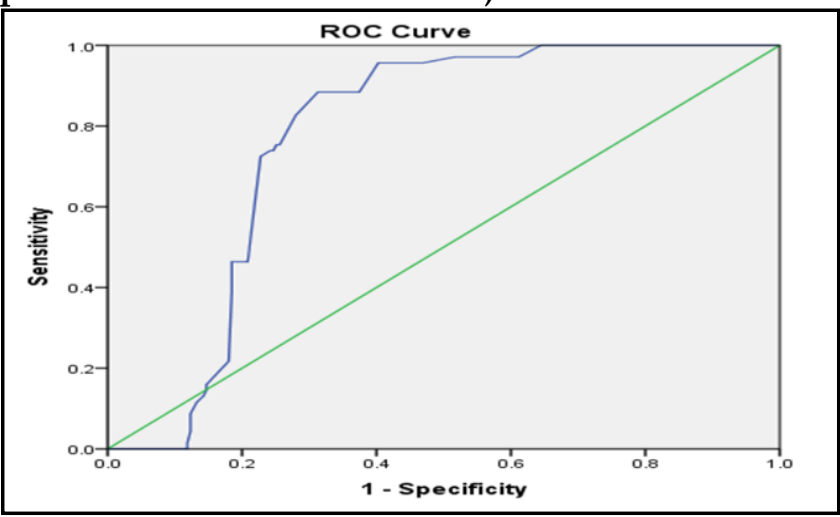

Figure-2: ROC curve showing AUC of impaired random glucose for prediabetes (impaired glucose tolerance) $69(n=280)$ patients are positive for impaired glucose tolerance on OGTT).

\section{DISCUSSION}

$\mathrm{DM}$ is metabolic chronic disease having very high prevalence of diagnosed and undiagnosed patients. ADA recommends early detection but prior efforts to screen for undiagnosed diabetes /prediabetes in population resulted in high expenditure as well as lowyield 5 . However, GomezPeralta et $a^{12}$, found that risk of undiagnosed 
diabetes in emergency department (ED) patients was $22.5 \%$ (95\% CI $16.4-28.5 \%)$ and screening with RPG and A1C was promising in such settings. This prospective study utilized opportunity of value of RPG among individuals undergoing DM diagnostic workup.

The study population consisted of 280 patients. Mean age as well mean IRG was found comparable in both genders. OGTT performed showed NG in 173 (61.8\%), prediabetes in 69 $(24.6 \%)$ and diabetes in $38(13.6 \%)$ patients. Significantly higher patients with diabetes and prediabetes were found if initial RPG and IFG were higher $(p<0.001)$ suggesting significant correlation between levels of RPG and chances of having undiagnosed diabetes or prediabetes. IRG $\geq 7.45$ $\mathrm{mmol} / \mathrm{L}$ was found $94.7 \%$ sensitive and $74.4 \%$ specific to diagnose patients with diabetes, albeit with lower sensitivity \& specificity for prediabetes.

Our results were in correlation with various studies carried out nationally as well as internationally ${ }^{13-15}$. Meek et al ${ }^{13}$, revealed that RPG $\geq 7.5$ mmol/1 had $90 \%$ specificity and $70 \%$ sensitivity for diagnosis of diabetes in pregnant while Zimmer et al ${ }^{14}$, identified optimal RPG $6.95 \mathrm{mmol}$ /1 (93\% specificity, 40\% sensitivity) and Ginde et $a^{15}$. $6.67 \mathrm{mmol} / 1$ (89\% specificity, 26\% sensitivity) albeit with lower sensitivity but comparable specificity to our results. The frequency revealed by our study was higher than figures quoted by diabetes association of Pakistan (DAP) 3 but similar findings were presented by Bahijri et al16, for Saudi Arabia which may be due to selection bias. Akhtar et al, found prevalence of diabetes and prediabetes $9.27 \%$ \& $11.43 \%$ respectively in a meta-analysis, prevalence of DM closely correlating with our study while that of prediabetes is lower. Similar figures are quoted by other studies conducted in various parts of Pakistan 18,19,20. Basit et al18,20, showed frequency of diabetes and prediabetes 26.3 \& $14.4 \%$ which was higher as compared to our findings. A study conducted by Barasch et al11, comprising subjects in 28 dental practices of National Institutes of Health (NIH) revealed frequency of $12.2 \%$ (51) for diabetes,
$5.7 \%$ (24) for pre-diabetes when RPG was followed by definitive test. Majority patients were male ( $54.3 \%$ vs $45.7 \%$ females); the mean age was $52.2 \pm 14.7$, sex ratio being comparable with our study while age being older.

Another study conducted by Charfen et al21, showed lower percentage of diabetes but higher for prediabetes when compared to our results. A RPG level $\geq 140 \mathrm{mg} / \mathrm{dl}(7.78 \mathrm{mmol} / \mathrm{l})$ triggered follow up testing at 06 weeks interval with OGTT. Twenty-seven (11\%) were found to have diabetes, 141 (55\%) had prediabetes, and 88 (34\%) had normal results. All at-risk subjects with a RPG >155 mg/ dL (8.6 mmol/L) had either prediabetes or diabetes on follow-up testing. In our study, none of the patients having IRG $<6.0 \mathrm{mmol}$ / $\mathrm{L}$ was found to have diabetes while 26 patients out of 42 having IRG $>8 \mathrm{mmol} / \mathrm{L}$ were diagnosed suffering from DM when underwent OGTT.

Silverman et al22, studied A1C as screening tool in acute care setting. Mean age was $49.7 \pm$ 14.9 years while on the basis of OGTT used a definitive test, the prevalence of previously undiagnosed prediabetes and diabetes was 31.9 and $10.5 \%$, respectively.

This study found statistically significant difference of RPG value between groups (F148.88, $p<0.001$ ANOVA). Moreover, IRG cutoff value $7.45 \mathrm{mmol} / \mathrm{L}$ suggested for screening was found consistent with international literature.George et al 23 found that $>50 \%$ patients presenting to the ED with undiagnosed diabetes having RPG $>7$ $\mathrm{mmol} / \mathrm{L}$ fulfilled criteria for IGM. Ziemer et al14, found that $7 \mathrm{mmol} / \mathrm{L}$ has $93 \%$ specificity and $40 \%$ sensitivity for identifying diabetes when various RPG cut-offs were analyzed while Ginde et al15, recommended value $\geq 120-140 \mathrm{mg} / \mathrm{dl}$ which is quite close to our findings. Rhee et al ${ }^{6}$, suggested $93 \%$ sensitivity and 59\% specificity of RPG $>130$ $\mathrm{mg} / \mathrm{dl}$ strongly supporting our value.

Keeping in view morbidity and mortality of DM and vast availability of RPG even at primary care level, it may provide new avenues to diagnose and treat the disease at the budding and prevent myriad of complications. 


\section{LIMITATION OF STUDY}

This study was carried out at two centers only leading to potential selection bias thus limiting generalizability of the results to population. Another limitation was lack of follow up and drop outs. Hence, these results must be interpreted with care. Moreover, determination of significant differences between groupsmay have been precluded by small sample size.

\section{ACKNOWLEDGMENT}

The authors acknowledge, with gratitude, Dr Sunmbal Nida (Department of chemical pathology, AFIP Rawalpindi), for her contribution to data collection.

\section{Disclosure}

This study was conducted at AFIP Rawalpindi/CMH Quetta after approval of synopsis from Research evaluation unit of College of Physicians and surgeons Pakistan and Ethical review board of AFIP / CMH Quetta.

\section{Author Contribution}

Mr. MTS had full access to all of the data in the study and takes responsibility for the integrity of the data and the accuracy of the data analysis.

\section{CONCLUSION}

There was a considerably high frequency of diabetes and prediabetes among healthy individuals and RPG helps diagnose these. IRG $\geq 7.45 \mathrm{mmol} / \mathrm{L}$ was found optimal to initiate definitive testingto identify undiagnosed patients with diabetes and prediabetes.

It is certified that this original work is submitted with PAFMJ for publication and has not been submitted anywhere else as per protocols in vogue.

\section{CONFLICT OF INTEREST}

This study has no conflict of interest to be declared by any author.

\section{REFRENCES}

1. Chatterjee S, Khunti K, Davies MJ. Type-II diabetes. Lancet 2017; 389(10085): 2239-51.
2. Cho NH, Shaw JE, karuranga S, Huang Y, da Rocha Fernandes JD, Ohlrogge AW, et al. IDF diabetes atlas: global estimates of diabetes prevalence for 2017 and projections for 2045. Diabetes Res Clin Pract 2018; 138(1): 271-81.

3. Aamir AH, Ul-Haq Z, Mahar SA, Qureshi FM, Ahmad I, Jawa A, et al. Diabetes prevalence survey of Pakistan (DPS-PAK): prevalence of type 2 diabetes mellitus and prediabetes using HbA1c: a population-based survey from Pakistan. BMJ Open 2019; 9(2): e025300-08.

4. Chan JC, Gregg EW, Sargent J, Horton R. Reducing global diabetes burden by implementing solutions and identifying gaps: a Lancet Commission. Lancet 2016; 387(10027): 1494-95.

5. American Diabetes Association. Prevention or delay of type 2 diabetes. Diabetes Care 2018; 41(Suppl-1): S44-54.

6. Rhee MK, Ho YL, Raghavan S, Yuk-Lam Ho, Raghavan S, Jason $\mathrm{L}$, et al. Random plasma glucose predicts the diagnosis of diabetes. PLoS One 2019; 14(7): e0219964-76.

7. Hu X, Zhang Q, Zeng T, Zhang JY, Min J, Tian SH, et al. Not performing an OGTT results in underdiagnosis, inadequate risk assessment and probable cost increases of (pre)diabetes in HanChinese over 40 years: a population based prospective cohort study [published online ahead of print, 2018 Dec 1]. Endocr Connect 2018; 7(12): 1507-17.

8. Thewjitcharoen $\mathrm{Y}$, Jones Elizabeth A, Butadej S, Nakasatien $\mathrm{S}$, Chotwanvirat $\mathrm{P}$, Wanothayaroj $\mathrm{P}$, et al. Performance of HbA1c versus oral glucose tolerance test (OGTT) as a screening tool to diagnose Dysglycemia status in high-risk Thai patients. BMC Endocr Disord 2019; 19(1): 23-31.

9. Sop J, Gustafson M, Rorrer C, Tager A, Annie FH. Undiagnosed diabetes in patients admitted to a clinical decision unit from the emergency department: A retrospective review. Cureus 2018; 10(10): e3390-95.

10. Friedman SM, Vallipuram J, Baswick B. Incidental findings of elevated random plasma glucose in the $\mathrm{ED}$ as a prompt for outpatient diabetes screening: a retrospective study. BMJ Open 2013; 3(12): e003486-89.

11. Barasch A, Gilbert GH, Spurlock N, Funkhouser E, Persson LL, Safford MM. Random plasma glucose values measured in community dental practices: Findings from the dental practicebased research network. Clin Oral Investig 2013; 17(5): 1383-88.

12. Gomez-Peralta F, Abreu C, Andreu-Urioste L, Antolí AC, RicoFontsaré C, Martín-Fernández D, et al. Point-of-care capillary HbA1c measurement in the Emergency Department: a useful tool to detect unrecognized and uncontrolled diabetes. Int J Emerg Med 2016; 9(1): 7-12.

13. Meek CL, Murphy HR, Simmons D. Random plasma glucose in early pregnancy is a better predictor of gestational diabetes diagnosis than maternal obesity. Diabetol 2016; 59(3): 445-52.

14. Ziemer DC, Kolm P, Foster JK, Vaccarino V, Rhee MK, Varughese RM, et al. Random plasma glucose in serendipitous screening for glucose intolerance: Screening for impaired glucose tolerance study 2. J Gen Intern Med 2008; 23(5): 528-35.

15. Ginde AA, Enrico Cagliero MPH, Nathan DM. Point of care glucose and hemoglobin A1C in emergency department patients without known diabetes: implications for opportunistic screening. Acad Emerg Med 2008; 15(12): 1241-47.

16. Bahijri SM, Jambi HA, Al Raddadi RM, Ferns G, Tuomilehto J. The prevalence of diabetes and prediabetes in the adult population of Jeddah, Saudi Arabia - a community-based survey. PLoS ONE 2016; 11(4): e0152559-64.

17. Akhtar S, Nasir JA, Abbas T, Sarwar A. Diabetes in Pakistan: A systematic review and meta-analysis. Pak J Med Sci 2019; 35(4): 1173-78. 
18. Basit A, Fawwad A, Qureshi H, Shera AS. NDSP Members. Prevalence of diabetes, pre-diabetes and associated risk factors: second National Diabetes Survey of Pakistan (NDSP), 2016-2017. BMJ Open 2019; 8(11): e020961-65.

19. Shera AS, Basit A, Prompt Team. Pakistan's recommendations for optimal management of diabetes from primary to tertiary care level (PROMPT). Pak J Med Sci 2017; 33(5): 1279-83.

20. Basit A, Fawwad A, Siddiqui SA, Baqa K. Current management strategies to target the increasing incidence of diabetes within Pakistan Diabetes Metab Syndr Obes 2018; 12(1): 85-96.
21. Charfen MA, Ipp E, Kaji AH. Detection of undiagnosed diabetes and prediabetic states in high risk emergency department patients. Acad Emerg Med 2009; 16(5): 394-402.

22. Silverman RA, Thakker U, Ellman T,Wong I. Hemoglobin $\mathrm{A} 1 \mathrm{C}$ as a screen for previously undiagnosed prediabetes and diabetes in an acute-care setting. Diabetes Care 2011; 34(9): 1908-12.

23. George PM, Valabhji J, Dawood M, Henry JA. Screening for type 2 diabetes in the accident and emergency department. Diabet Med 2005; 22 (12): 1766-69. 